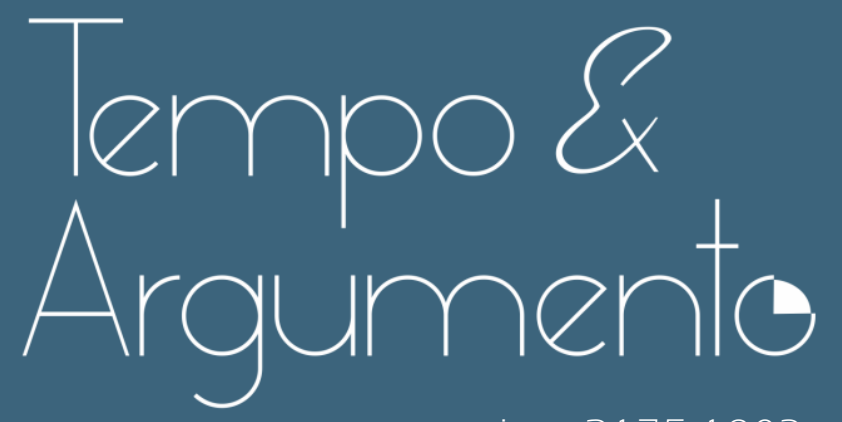

e-issn 2175-1803

El sexo de las naciones: producción y circulación global de narrativas de la trata de blancas en la Argentina (1900-1936)

- Patricio Simonetto

Doctor en Ciencias Sociales y Humanas por la Universidad Nacional de Quilmes (UNO). Consejo Nacional de Investigaciones Científicas y Técnicas (CONICET). Buenos Aires - ARGENTINA unq.edu.ar/comunidad/ 1 105-patricio-simonetto.php patriciosimonetto@gmail.com

(D) orcid.org/0000-0001-5906-7072

Para citar este articulo:

SIMONETTO, Patricio. El sexo de las naciones: producción y circulación global de narrativas de la trata de blancas en la Argentina (1900-1936). Tempo e Argumento, Florianópolis, v. 12, n. 29, e0201, jan./abr. 2020

doi http://dx.doi.org/10.5965/2175180312292020e0201

Recebido: 23/10/2018

Aprovado: 23/10/2019 


\title{
El sexo de las naciones: producción y circulación global de narrativas de la trata de blancas en la Argentina (1900- 1936) $)^{1}$
}

\begin{abstract}
Resumen
El objetivo de este artículo es estudiar la producción, circulación y reapropiación de narrativas en torno a la trata de blancas en la Argentina en el primer tercio del siglo XX. El texto tiene 3 argumentos. Primero, distintos actores apelaron a la figura del rufián para disputar una reinterpretación de la Argentina como comunidad imaginada frente a la crisis política y cultural del proyecto liberal. Segundo, las redes de galenos, funcionarios y los organismos internacionales desplegaron una agenda social que apostó a la reposición de la maternidad como horizonte femenino para hacer frente a las perturbaciones de la modernidad capitalista. Tercero, la definición de las políticas frente a la venta y compra de sexo despertaron conflictos al interior de estos organismos entre polos centrales y periféricos. Para llevar adelante este estudio, analizamos prensa periódica y especializada, libros de galenos, juristas y periodistas, documentos oficiales y Expedientes del Congreso de la Nación Argentina.
\end{abstract}

Palabras clave: Proxenetismo. Prostitución. Sexualidad. Nación. América Latina.

\section{Sex of the nations: production and global circulation of narratives about trafficking in white women in Argentina (1900-1936)}

\begin{abstract}
This article aims to study the production, circulation, and reappropriation of narratives about trafficking in white women in Argentina in the first third of the $20^{\text {th }}$ century. The text has 3 arguments. First, various players appealed to the figure of the ruffian to dispute a reinterpretation of Argentina as an imagined community in face of the political and cultural crisis of the liberal project. Second, the networks of physicians, officials, and international organizations deployed a social agenda that bet on a revival of motherhood as a feminine horizon to tackle the disruptions of capitalist modernity. Third, the definition of policies regarding the sale and purchase of sex aroused conflicts within these organizations between central and peripheral poles. To carry out this study, we analyze periodic and specialized press media, books by physicians, jurists, and journalists, official documents, and proceedings of the Congress of the Argentine Nation.
\end{abstract}

Keywords: Procuring. Prostitution. Sexuality. Nation. Latin America. 


\section{Introducción}

En su tesis para obtener el título de abogado, el escritor nacionalista Manuel Gálvez (1905) escribió que

[...] de aspecto aparatoso, tiene el caften el afán de una charra ostentación. Viste con cierto lujo - un lujo de prostíbulo - donde todo es relumbrón y cursi. Los enormes anillos en la mano izquierda, el bastón de puño de oro, la corbata de un rojo aborrachado, el pañuelo de seda excesivo y ridículo; son sus indispensables atavíos. Su característica es una exagerada ambición de dinero [...] Ha olvidado el sexo para buscar la fortuna.

Figuras paradigmáticas de comienzos del siglo XX, los proxenetas llamados caftens, rufianes o canflineros - fueron narrados por escritores, periodistas, viajeros, diputados, sindicalistas, burócratas y funcionarios.

Actores visibles de una ciudad en crecimiento, los rufianes fueron también objetos de una imaginería con las que se los dotó como portadores de los males de la modernidad urbana: egoísmo, frivolidad y afeminamiento. Veinticinco años después de la narración de Gálvez (1905), un proceso judicial contra 108 varones acusados de pertenecer a la falsa sociedad judía Zwy Migdal conmocionó a la Argentina. Los “tenebrosos" israelitas ocuparon las páginas de los periódicos que desvelaron las tramas de una sociedad civil fundada en 1906 que, según sus relatos, contaba con una falsa sinagoga y un cementerio propio (CRÍTICA, 10/09/1930). Un año más tarde, el juez liberó a 105 de los acusados por falta de pruebas (LA RAZÓN, 27/01/1931). El impacto de este proceso convergió con los esfuerzos de las redes globales de activistas y funcionaron que tras muchas presiones lograron que el Estado Argentino promoviera en 1936 una ley que abolió el sistema de burdeles patentado que funcionaba desde 1875 (GUY, 1991; BIERNAT, 2013; SIMONETTO, 2019a).

Los temores desplegados en torno a los proxenetas cumplieron un doble papel en la agenda local e internacional. Primero, sus figuras colaboraron en la reconfiguración del imaginario nacional, que se consolidó frente a la crisis del proyecto liberal, en las décadas de 1920 y 1930. Su irrupción - al igual que las imágenes sobre anarquistas y comunistas - coagularon el declive de la esperanza de las elites puesta en la migración como un factor de modernización y una reinterpretación de la Argentina como signo antitético a factores considerados 
El sexo de las naciones: producción y circulación global de narrativas de la trata de blancas en la Argentina (1900-1936)

Patricio Simonetto

adversos y foráneos. En este sentido, planteó que existieron profundas interconexiones en los que los proxenetas constituyeron enclaves en torno a los cuales se articularon nociones sexuales y procesos de racialización que redefinieron la masculinidad blanca como un valor cultural dominante de la Argentina $^{2}$. Segundo, los circuitos y las redes de activistas y funcionarios vinculados con organismos internacionales se apropiaron de estas narrativas para promulgar medidas que proponían la re-maternalización de lo femenino como una vía para desarmar el peligro que significaba la meretriz. Sin que por ello no existieran tensiones.

Desde la década de 1980, la historiografía indagó la "prostitución” urbana restituyendo el papel de las mujeres en la construcción de subjetividades (WALKOWITZ, 1982; GUY, 1991; CORBIN, 1996; GILFOYLE, 1999). La proliferación de estudios amplió las temáticas: cuestionó las narrativas moralistas que permearon el discurso estatal del siglo XX (BARTLEY, 2012), se concentró en la acción de vender sexo en las metrópolis (GARCÍA, 2012), reconoció nuevos actores como los proxenetas (SCHETTINI, 2014; CHAUMONT; RODRIGUEZ GARCIA; SERVAIS, 2017; LAITE, 2017), los clientes (LAITE, 2011; SIMONETTO, 2018b), y los varones que ofrecieron sexo por dinero (REVENIN, 2005; SIMONETTO, 2018a).

La historiografía argentina estudió la modulación estatal y médica de la prostitución como una intervención sobre la sexualidad y la salud (MILANESIO, 2005; BIERNAT, 2007; MIRANDA, 2012; QUEIROLO, 2014), analizó la circulación de mujeres a principio de siglo XX (SCHETTINI, 2014), describió sus vínculos con la cultura popular (GUY, 1991), narró la acción de proxenetas y prostitutas de origen judío (YARFITZ, 2012), destacó el papel del crecimiento urbano y las prácticas de mujeres en los burdeles durante la reglamentación (MÚGICA, 2001; BEN, 2014), y exploró su vida en zonas rurales (LINARES, 2016). En este sentido, mi trabajo refuerza a la historia social y cultural de los proxenetas como actores normalmente relegados por la historiografía (YARFITZ, 2012).

El objetivo de este artículo es estudiar la producción, circulación y reapropiación de narrativas en torno a la trata de blancas - entendida como una categoría nativa - y los circuitos globales (como las comisiones de la Sociedad

\footnotetext{
2 Racialización es un proceso que hace legible ciertas diferencias como signos de jerarquización afincados en legados coloniales y nacionales (APPELBAUM; MACPHERSON; ROSEMBLATT, 2003; ARIAS; RESTREPO, 2010).
} 
de Naciones [SN]) que la interconectaron en los debates públicos por una política frente a la comercialización de servicios sexuales. Lejos de negar las prácticas y los sentidos apelados por varones que se apropiaron del dinero de mujeres que vendieron sexo.

Para ello, se abordaron distintas fuentes documentales, como artículos de prensa, publicaciones oficiales, memorándums de entendimiento y reportes de especialistas de la SN, presentaciones personales de la Cámara de Diputados, artículos y libros de galenos, como también documentos del Estado Argentino. Los documentos analizados son considerados representativos de un cuerpo más extenso de una investigación de larga data que incluye expedientes judiciales, legajos de la cárcel, publicaciones médicas, entre otras (SIMONETTO, 2019a). Documentos que fueron abordados en el cruces entre la historia social y los estudios culturales para entender las disputas en la producción de sentido con las que se experimentó la visibilidad de los proxenetas en la vida pública (TENTI, 2012).

Mi recorte temporal abarca desde el inicio del siglo hasta la sanción de la Ley de Profilaxis Social (1936), que daría fin al sistema de burdeles patentados, señalado como el principal responsable de la consolidación de la práctica de proxenetismo. A su vez, mi perspectiva espacial interconecta a sujetos, publicaciones, y figuras que conectaron espacios más allá de las fronteras nacionales, tal como fue expuesto recientemente por la historia global.

El artículo se organiza en dos apartados. El primero describe las representaciones racializadas y sexuadas de los rufianes en la Argentina. Aquí, explicamos cómo distintos actores utilizaron a estas figuras para redefinir su imaginario de nación. El segundo estudia las políticas recomendadas por la SN, las redes de organismos públicos y civiles, y sus procesos de reconfiguración. Tercero, presentamos las tensiones desplegadas en torno a la política de la SN en América Latina.

Los rufianes ideales: la racialización sexual de la nación

En un compendio de recortes de noticias, el escritor Pablo Urbanyi recolectó el "Paísano Díaz" y fue considerado una figura canónica del "mundo de 
El sexo de las naciones: producción y circulación global de narrativas de la trata de blancas en la Argentina (1900-1936)

Patricio Simonetto

las esclavas blancas". Era un canflinero, también llamado por periodistas y policías como canflinflero o panzón criollo, un argentino cuya tarea era "introducir" a las mujeres en los lenocinios locales. El seudónimo destacaba su criollismo frente al sobrenombre de los rufianes o caftens de origen foráneo. Se lo contrastaba al "tano Mussolino", un italiano descripto como lujurioso, amante de las prendas y generoso con sus aliados (URBANYI, 1976) 3 .

La prensa los reseñó como varones obsesionados con su aspecto físico, hecho que resquebrajaba su imagen masculina. Se destacaba que en sus concurridas fiestas asistían homosexuales donde los "maricones eran bastante visibles" (URBANYI, 1976, p. 80). Eran representados como lascivos que vestían pantalones de fantasía, sacos cruzados negros, pañuelos de seda, y gemelos de plata. Sus figuras fueron sobrecargadas con un halo ficcional que destacó su perversidad recurriendo a aspectos maniqueos de la cultura melodramática: eran personajes materialistas, insensibles, racionalistas y ostentosos, capaces de renunciar a una libido masculina aceptada en el período como incontrolable por el afán egoísta del dinero.

Los ecos de su existencia y sus registros se replicaron a lo largo del tiempo y el globo. A mediados de siglo, un sindicalista de extracto peronista alertó a sus compañeros sobre los peligros que significarían volver a reglamentar la prostitución, dejando vía libre a los "tenebrosos de la Zwy Migdal" (QUEVEDO, 1952).

Tan reales como ficcionales, los rufianes jugaron un papel en la reinterpretación de la imaginación argentina. Un traspié al sueño modernizador de la Argentina blanca de la inmigración (GARGUIN, 2007), que se transformó sus reglas frente a personajes que coagularon los temores de una ciudadanía imaginada como amenazada por los efectos desintegradores de la modernidad urbana. Los rufianes fueron progresivamente bosquejados como antítesis del orden nacional, con lo que se trazaron fronteras de género, clase, y raza.

Desde mediados del siglo XIX y a principios del siglo XX, distintas interpretaciones de la movilidad - forzada o consensuada - de mujeres y varones

\footnotetext{
Pablo Urbanyi nació en Hungría en 1939, migró a la Argentina a los 7 años y se nacionalizó. Periodista de La Opinión, presentó el libro El mercado erótico como una de las revisiones y compilaciones más completas de fuentes periodísticas y policiales sobre los proxenetas en 1930.
} 
que participaron de la venta de sexo, fue mediada por la circulación de narrativas globales con traducciones locales, del llamado problema de la trata de blancas (PISCITELLI, 2012). La sexualización de la cultura pública en occidente empujó el declive de la esperanza puesta en los burdeles patentados y se propuso una reorganización del paradigma heterosexual, el abandono tutelar de una relación que se consideró complementaria del matrimonio monógamo, para desplegar una incipiente batería que ponía la atención sobre el sexo premarital (HERZOG, 2011; STEARNS, 2017).

El concepto white slavery se originó en Estados Unidos (EE. UU.). En 1830, los trabajadores blancos la emplearon para comparar su situación con la de los esclavos negros (ROEDIGER, 1999). Durante el siglo XIX, el término se popularizó para describir problemas económicos y políticos. A finales de siglo, los círculos que bregaron por la abolición de la prostitución reglamentada y los reformistas sociales tradujeron el concepto y lo dotaron de una connotación sexual. Josephine Butler, exponente británica del incipiente movimiento abolicionista, escribió en 1870 que mientras se derogaba la esclavitud racial se permitía la tiranía sobre las mujeres (JORDAN, 2007). Discurso que se enlazó y vinculó con los temores globales asociados a la vida de los "bajos fondos", que desde el siglo XIX funcionó como soporte de una plataforma de pensamientos sociales que buscaron reformar para soslayar los efectos de las sociedades contemporáneas (KALIFA, 2013).

En el paso del siglo XIX al XX, los Estados modernos incrementaron su atención por la consolidación de las fronteras nacionales. El énfasis sobre las asociaciones delictivas internacionales canalizó las ansiedades generadas en la elite sobre una identidad que sentían perturbada (GALEANO, 2009; KNEPPER, 2011). La idea del robo, la llegada o la captura de mujeres secuestradas movilizó la proliferación de historias sobre el tráfico de mujeres europeas engañadas. En los países sudamericanos, estos relatos coagularon preocupaciones sobre los efectos de la inmigración masiva y sus variadas interpretaciones ayudaron a definir la relación entre ciudadanía y nación (DEVOTO, 2001; SCHETTINI, 2014; YARFITZ, 2012). Las campañas contra la trata de blancas fueron también una reacción a las transformaciones sexuales de la cultura occidental y a la globalización del mundo, que implicó el "acceso sexual" de varones de las 
periferias a las mujeres del occidente europeo. Por ello se destacó que la preocupación de los abolicionistas criollos por la imagen global de Argentina como país receptor de mujeres formó parte de un proceso de traducción local de los juicios morales de una cultura sexual europea en expansión (STEARNS, 2017).

La impregnación en estas narrativas de un discurso dirigido sobre ciertas comunidades étnicas, como la judía, se inscribe en un proceso de transformación de la imaginación nacional durante las décadas de 1920 y 1930. El agotamiento de la referencia a la inmigración como solución de la escasez de población argentina para la construcción de una mano de obra moderna convergió con las tensiones entre la referencia de un sector de la elite social y cultural al criollismo como metáfora del país rural agroexportador y la emergencia de la identidad porteña como constructora de referencia de capas medias urbanas cosmopolitas (NOUWEN, 2013; ADAMOVSKY, 2016).

Hasta la década de 1920, las publicaciones de las feministas locales no condenaron moralmente a las prostitutas, ni dieron un espacio relevante a la trata de blancas. Fueron la médica suizo-argentina Petrona Eyle y la farmacéutica ítalo-argentina Julieta Lanteri, ambas pioneras del feminismo argentino, las que desde distintas variantes se ocuparon del asunto. Eyle fundó, en 1924, la Liga Contra la Trata de Blancas, en consonancia con sus pares inglesas, se sumó a las denuncias sobre la explotación sexual de mujeres en el país y promovió el derecho de los niños y el feminismo. Lanteri dedicó un particular rechazo a la prostitución reglamentada en el Congreso Internacional Femenino, que reunió a mujeres socialistas, librepensadoras y reformistas, en el que exigió que el mismo se posicionara por el rechazo a la prostitución por entenderlo como un efecto de la desigualdad entre los sexos (BARRANCOS, 2008; VALOBRA, 2008).

Las narrativas sobre el tráfico de mujeres y las imágenes de los proxenetas fueron emprendidas por escritores, intelectuales, periodistas, y burócratas. Los círculos de intelectuales nacionalistas disputaron la interpretación racial de este concepto en vistas de una articulación general de la nación y sus ciudadanos con preceptos étnicos (blancos), genéricos (masculinos), y clasistas. 
El sexo de las naciones: producción y circulación global de narrativas de la trata de blancas en la Argentina (1900-1936)

Patricio Simonetto

La revista ilustrada El Gladiador publicó una imagen que catalizó la representación canónica de los proxenetas: un varón blanco, con buenas ropas y con un látigo dominando a un grupo de mujeres consternadas colocadas en un margen inferior, abrumadas (Figura 1). La inclusión de esclavos negros y la leyenda inferior expresan, en un lenguaje crítico, la referencia al término trata de blancas para referir al resquemor por el desplazamiento de una esclavitud racial hacia una sexual. El proxenetismo era, así, un factor que degradaba una feminidad blanca al colocarla al mismo estatus que la negritud. "lo que va de ayer a hoy" no es más que el temor por una transformación en la que las fuerzas perturbadoras de una modernidad urbana amenazarían a lo femenino como un componente del imaginario sexual de la nación al suponerlo equivalente a la degradación desplazada desde fronteras étnicas exógenas.

Figura 1. El Gladiador, 1902.

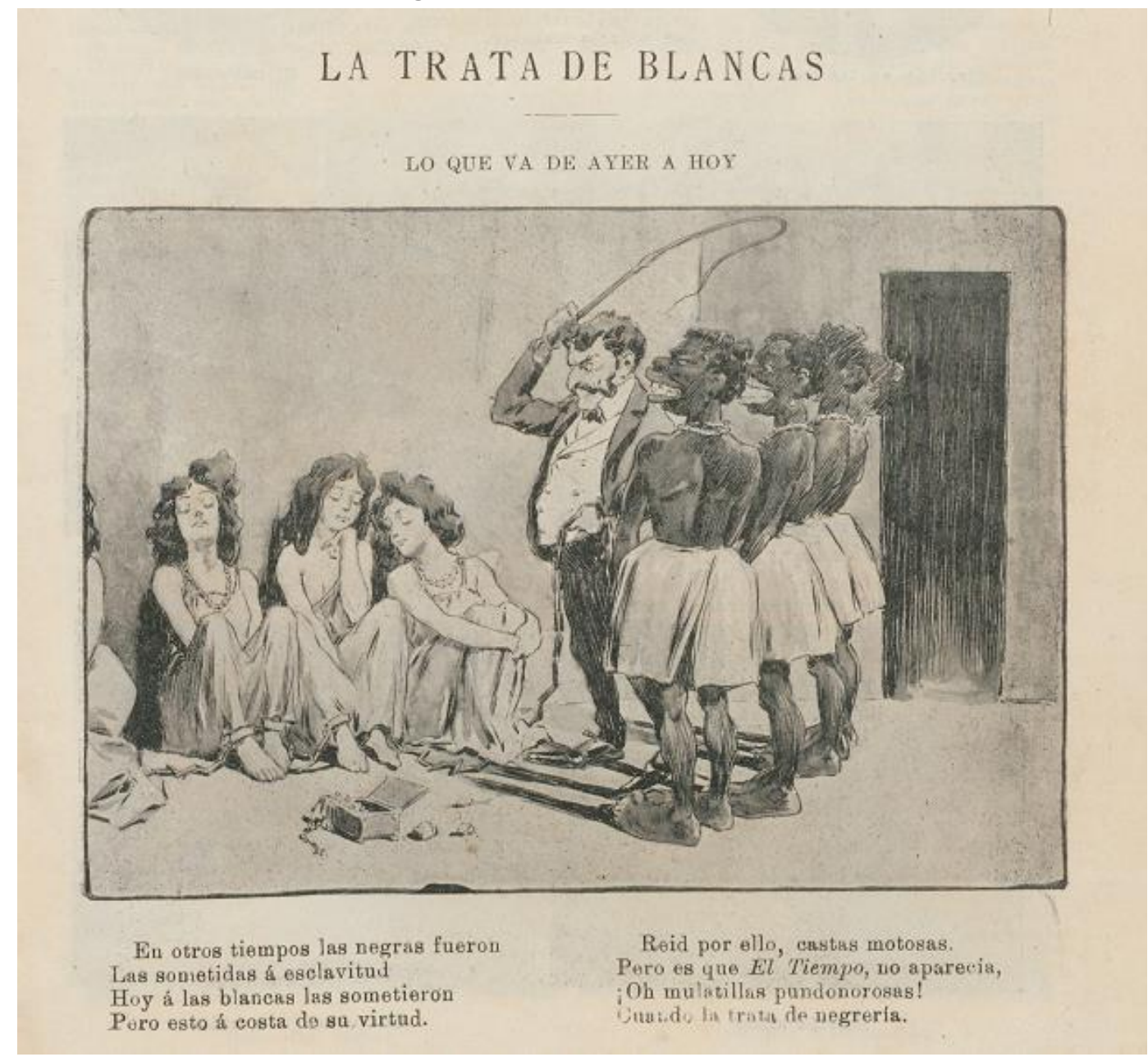

Fuente: Archivo Instituto Iberoamericano de Berlín, Alemania. 
Como destacamos en la introducción, figuras influyentes como Manuel Gálvez (1905) dieron un importante sitio al carácter femenino, vanidoso y corrupto de los proxenetas como elementos disonantes de la nación. La creciente visibilidad que adquirirían y que llegaría a cenit en el juicio contra los "108 tenebrosos de la Zwy Migdal” (CRÍTICA, 10/09/1930) convergió con narrativas nacionalistas que intentaron dar respuesta a la "crisis" reinterpretando la "nación" bajo un prisma étnico.

El nacionalismo argentino consideraba que el poderío de la nación estaba construido sobre la familia heterosexual, con autoridad masculina y una división rígida en los papeles de esposas y maridos, por lo que, el fin del matrimonio era la reproducción de la raza (DEUTSCH, 2005). Para Manuel Gálvez (1905), la sensualidad importada del exterior era una amenaza para la firmeza viril y la pureza criolla. Las energías sexuales que se encarnaban en las mujeres europeas de los burdeles porteños impulsaban la corrupción de los hogares, lo que promovía, así, que más mujeres se dedicaran al "triste negocio de la prostitución". Leopoldo Lugones (1930) culpó al liberalismo de problemas como la prostitución, el aborto, y la pobreza. El autor identificó en la llegada de extranjeros, en un contexto de creciente urbanización, el causante de la degeneración nacional y coincidió con los relatos internacionales que ubicaron a Buenos Aires como el centro de la prostitución y el libertinaje.

La sobredimensión que ocupó la presencia de judíos en los grupos de proxenetas como un factor descriptivo operó como una vía de estigmatización (YARFITZ, 2012). También la construcción racial tenía derivas políticas: para los nacionalistas, la perversión del judaísmo y de los países del este europeo se enlazaba en fabulas sobre la aparente participación de los comunistas en los delitos (DEUTSCH, 2005). El énfasis contra la comunidad israelita se inscribía en un pánico moral por los efectos perniciosos de la migración. Funcionarios de línea conservadora, como el diputado nacional Lucas Ayarragaray (1937), de la provincia de Entre Ríos, miembro de la Academia Nacional de Medicina y la Academia Nacional de Historia, destacaron que mientras esta inmigración dañaba los valores éticos de la Argentina, las pretensiones lujuriosas de las mujeres 
locales las dejaba expuestas a la degeneración foránea y que esto debía detenerse con el fin de ubicar a la Argentina como patrimonio de la raza blanca.

La construcción de la Argentina blanca actuó como un gran parangón desde el que se ponderó un supuesto destino desarrollado del país por sobre el resto del cono sur, un reservorio paradójico desde el cual se integraron amplias franjas de la población mediante políticas de blanqueamiento, como también, un reservorio de jerarquización (ALBERTO; ELENA, 2016). El despliegue narrativo sobre la trata de blancas fue apelado por actores para disputar su interpretación de la nación y, en este sentido, reforzar la construcción de la ciudadanía nacional como una frontera que ponderó lo blanco como una entidad pasiva pasible de perturbación foránea. Por lo tanto, la apelación al mundo criollo y rural actuó para los grupos dirigentes tradicionales como una referencia de la afirmación de su legitimidad y el rechazo a la presencia inquietante del extranjero (ADAMOVSKY, 2014).

A diferencia de los nacionalistas, los socialistas pugnaron por interpretar el fenómeno como un problema social producto de la "miseria capitalista" nacional y extranjera. Los socialistas reformistas argentinos ocuparon un lugar central en las transformaciones legales y fueron representantes pioneros contra la prostitución reglamentada (GUY, 1991). Diputados, como Alfredo Palacios y Ángel Giménez, no escatimaron críticas en un sistema que consideraban que dañaba la salud de los trabajadores varones, porque no limitaba la propagación de enfermedades venéreas. Afirmación con la que se inscribían en un consenso médico entre católicos, conservadores, y socialistas en el que la salud era comprendida en clave androcéntrica. Por ello, promovieron medidas para sancionar la explotación sexual, entre las que se destaca la "Ley Palacios", de 1913, una normativa pionera para la persecución de proxenetas que propuso penas desde 1 a 2 años (GIMÉNEZ, 1919, 1930).

Como un puerto que recibió multitudes migrantes, Buenos Aires fue definido como un foco de la amenaza. Como emergente de la "crisis urbana", se enfatizó el desorden de la metrópolis y sus amenazas (CAIMARI, 2012; KALIFA, 2013). La ciudad adquirió esta reputación remarcada por organismos internacionales. En el Boletín del Patronato Real para la Represión de la Trata de 
Blancas (1914, p. 166), de España, se indicaba que en la capital "los hombres tienen demasiado dinero sobre el vicio y no hay opinión pública sobre la moral”.

La prensa jugó un factor central en la delimitación nacional e internacional del problema. Los periódicos sajones destacaron el lugar de Buenos Aires como capital del tráfico de mujeres (KNEPPER, 2011). Las abolicionistas sajonas se esforzaron por contrastar su sistema legal con el reglamentario latino y, en este enfrentamiento, concentraron el foco de su discurso contra la capital argentina, destacando cómo el descontrol producido por la oleada migratoria era una muestra de la forma desdeñable con la que los funcionarios lidiaron con el comercio sexual (SCHETTINI, 2014).

La extraordinaria visibilidad implicó también el despliegue de un nuevo aparto léxico. Los periodistas usaron palabras tales como canflinero, caften, cafishio, chulo, souteneur, maqureau, hewreman, ricotaro, entre otras (BARRÉS, 1934). Un manual de la Policía de la Ciudad de Buenos Aires definía al rufián como aquel tratante que se encargaba del comercio de mujeres y al canflinero como un explotador subordinado argentino cuya tarea era ejercer el control físico sobre las mujeres (PAREJA, 1937). Otra publicación de la fuerza reconocía a los rufianes como quienes contactaban dueños de prostíbulos y podían explotar a 2 o 3 mujeres, lo que se diferenciaba de quien solo explotaba a su concubina o conyugue - canflinero (PINAZO, 1918).

La policía apeló al concepto de "amoral" para nominar tanto a homosexuales como a proxenetas. La referencia indicaba una ruptura de la condición moral ontológica adjudicada a lo masculino: la heterosexualidad y la actitud caballeresca frente a la mujer. Por la supuesta devoción de los proxenetas por las ropas estrafalarias, como también, por la convivencia con los prostitutos llamados cocots, se los relacionó con homosexuales afeminados, como "La Teresita", hijo de un antiguo comerciante, y se lo describía como "afeminado y no mal parecido" que "disfrazado de mujer y vistiendo elegantísimos trajes, se dio maña para conquistar a no pocos americanos, recibiendo cuantiosos regalos", por lo que "llegó a ser su sodomitismo escandaloso" (BEMBO, 1912).

La prensa nacional construyó un imaginario abominable de los explotadores sexuales. Las denuncias contra la Zwy Migdal se propusieron revelar 
su lugar como una institución poderosa y sin límites que convocó a periodistas de investigación a efectuar numerosas indagaciones a lo largo del siglo XX. Periódicos como Crítica (27/05/1930) destacaron la inoperancia policial con bromas ilustradas en las que signaban: “- ¿Sabes por qué la policía no dio a tiempo con la Migdal? Porque sufría de amigdalitis". Otras ilustraciones lo destacaban como varones trajeados que arrastraban a mujeres harapientas del pelo por el suelo de un burdel e insistieron en su proveniencia extranjera (CRÍTICA, 01/05/1930).

Las distintas interpretaciones de esta narrativa colaboraron con la proliferación de una batería de propuestas con las que se intentó reorganizar el paradigma de la sexualidad heterosexual como garantía de la modernización nacional. A la abolición de los burdeles patentados que se cristalizó en 1936 como sinónimos de la convergencia entre presiones internacionales, las redes de funcionarios y organismos locales - entre los que los galenos tuvieron un papel destacado - se le agregaron otras medidas con las que progresivamente el Estado intentó regular el carácter sexuado del espacio urbano, articulando preceptos que refirieron a la moral pública. La sanción progresiva de códigos de falta que primaron en las distintas jurisdicciones durante la totalidad del siglo XX, más allá de la alternancia entre gobiernos civiles y militares, dotó de capacidades punitivas a oficiales de la policía para penar las actividades de prostitutas, homosexuales, jóvenes, pobres y, en menor medida, proxenetas (SIMONETTO, 2019a). La sanción de normativas canalizó, entonces, una solución a una nación imaginada como perturbada en la que los intentos de reflotar una deriva étnica se diluyeron en medidas con anclaje en el género y la clase.

Es difícil imaginar que la síntesis de los conflictos despertados en torno a la figura pública de los proxenetas se tradujera en políticas transparentes. A partir de la década de 1930, la referencia al término raza mixturada con los imaginarios del poblacionismo y la eugenesia fue reinventada principalmente por médicos como horizonte de sentido del desarrollo de una población capaz de reproducirse y poblar la patria de soldados, trabajadores, y consumidores. A las medidas de organización punitivas las acompañaron las incipientes políticas 
El sexo de las naciones: producción y circulación global de narrativas de la trata de blancas en la Argentina (1900-1936)

Patricio Simonetto

sociales que ampliaron el acceso a derechos en vistas de mejorar cualitativa y cuantitativamente la población (Simonetto, 2019a).

La producción de la trata de blancas: narrativas globales, redes de activistas y funcionarios

Las narrativas locales se produjeron en vínculos con redes transnacionales de miembros de organismos civiles, médicos, criminólogos, y legisladores que confeccionaron una agenda global en torno al tráfico de mujeres con fines de explotación sexual. La historiografía destacó las prescripciones morales, ancladas en nociones de género y clase que cimentaron los argumentos de los organismos internacionales (CHAUMONT; RODRIGUEZ GARCIA; SERVAIS, 2017). Por ello se señaló la dificultad para estos organismos de construir categorías capaces de discernir procesos de movilidad de mano de obra y del "tráfico de personas" (SCHETTINI, 2014). La imagen de la mujer de finales del siglo XIX como una mujer blanca, tímida, y bella mutó durante el siglo XX hacia la mujer pobre y sin educación de países periféricos (LAITE, 2017).

El análisis diferenciado de redes locales e internacionales de administradores públicos y miembros de organizaciones civiles permite observar cómo interactuaron las dinámicas sociales dentro y fuera del territorio. Asumimos que las intenciones de estos organismos tuvieron como expresión máxima de presión y tensión la elaboración del informe sobre tráfico de personas de 1927 procurado por la SN que, con el financiamiento de entidades privadas, como la Fundación Rockefeller y la American Social Higyene Asociation, desplegaron una investigación en 112 ciudades de 28 países y 6.500 entrevistas en 14 lenguas.

Mientras que EE. UU. decidió retirarse de las actividades de la SN, la Fundación Rockefeller tomó la iniciativa de brindar financiamiento a comisiones específicas para modular sus intervenciones en políticas concretas. Era parte de una política continental de la fundación que, durante el siglo XX, consolidó con el apoyo económico a agencias sanitarias e instituciones de ciencias sociales. De esta forma, el sueldo de los investigadores que, desde 1924, trabajaron en la elaboración del informe se sostuvo con el apoyo del Bureau of Social Hygiene of 
New York City, de John D. Rockefeller Jr., quien ya había financiado otras investigaciones sobre la temática como la "Prostitution in Europe", de 1914, y "Commercialized Prostitution in New York City", de 1913. Rockefeller explicitó que su apoyo tenía como fin "luchar contra las fuerzas del mal", las que asociaba al sistema de prostitución reglamentada. Por su parte, el experto belga Isidore Maus fue categórico cuando, en 1924, escribió que la intención de la SN era "acabar con la prostitución reglamentada" (CHAUMONT; RODRIGUEZ GARCIA; SERVAIS, 2017).

La SN canalizó dos tendencias.

Primero, construyó una narrativa que redujo a las relaciones sexocomerciales a un signo univoco y estableció responsabilidades diferenciadas entre los países. El énfasis sobre los países latinoamericanos, sobre todo Argentina, se condice con una crítica profunda a aquellos Estados que sostuvieron una política de reglamentación de burdeles. De esta forma, el comité sobre la cuestión de la abolición de las casas de lenocinio y de la prostitución reglamentada dio cuenta, a través de los boletines, de las progresivas adhesiones a los convenios internacionales y a la desregulación de los burdeles. Durante las décadas de 1920, 16 Estados nacionales se deshicieron de su política de regulación, reafirmando los compromisos asumidos. En 1936, la comisión festejaría los avances legislativos en Bélgica, Egipto, Francia, y México (Boletín de la Sociedad de Naciones [BSN], 1936). En América Latina, la ley votada en Buenos Aires fue festejada como un triunfo sobre una capital que era imaginada como el centro de la circulación de prostitutas, una ley que se ponía en sintonía con las normativas de Cuba, de 1925, República Dominicana, de 1926, Montevideo, de 1927, Nicaragua, de 1928, y Chile, de 1931.

Segundo, la comisión constituyó su política unificando el debate sobre la trata de blancas con las políticas de asistencia materno-infantil. Operación por la que, simbólicamente, asumía la necesidad de intervención del Estado para restituir una posición maternal ontológica al ser femenino, perturbada por la miseria condensada en la figura de la prostituta. Es decir, que intervino para materializar la frontera cultural entre la madre y la meretriz. La definición del binomio madre/hijo como sujeto de las políticas se plasmó en la lenta 
confluencia de instancias institucionales y distribución de recursos que tendieron a constituirlos sujetos de políticas sociales (BIERNAT; RAMACCIOTTI, 2008). Desplazando al tráfico de personas de la agenda criminológica, sin perder las pretensiones punitivas al proxenetismo, pero reubicándolo en una agenda más amplia que la SN llamaría de cuestiones "sociales y humanitarias".

Las graves consecuencias demográficas que afectaron a la Europa de entreguerras promovieron la emergencia de un interés principal por tutelar el "capital humano" (SCARZANELLA, 2005). Por lo que muchos Estados respondieron con políticas que tendieron a ampliar su base social, mediada por una fuerte marca de género. Mientras se impulsó extender los derechos soslayados por las miserias bélicas, interconectando la idea de naciones en particular con la preocupación por la acumulación de un capital humano capaz de trabajar y defender las tierras, de poblar y de laborar la nación, lo que implicó una renovación normativa de una ciudadanía sexuada. La SN desplegó una agenda en torno a la trata de blancas que fue objeto de usos, intervenciones, apropiaciones, y traducciones en la batalla particular por definir el régimen de administración de la venta de sexo.

Por ello, la consolidación de una agenda de protección con una impronta tutelar se condijo con políticas nacionales que reafirmaron el núcleo simbólico madre/prostituta como horizonte femenino. Es factible que fuera de conjunto, resultado paradójico de la Primera Guerra Mundial sobre la experiencia de las mujeres europeas. Mientras los varones se concentraron en los frentes de batalla, las mujeres vivieron una relativa libertad y responsabilidad al reconfigurar su participación en lo público, reemplazaron a los hombres en numerosos puestos de trabajo y fueron las responsables de garantizar la reproducción social de las familias. Pero, a su vez, este fenómeno marcó una experiencia que se condensó en una exaltación de su rol maternal y concentró la figura de la madre como salvaguarda de la nación (THÉBAUD, 1993). Aunque la guerra no supuso un momento neto de liberación en la década de 1920 y la década posterior, un proceso de reacción, es posible que la emergencia de una agenda de protección se asentara en la tendencia conservadora del proceso para reprivatizar la presencia femenina. 
Es difícil mesurar el impacto de estas políticas en cada caso nacional. Lewis Hackett, funcionario estadounidense de la Fundación Rockefeller, sostuvo en sus diarios de viajes por Latinoamérica que los cambios en las normativas argentinas en torno a la prostitución eran la muestra de la ignorancia de los funcionarios. En una cena que mantuvo con José Puente, jefe de la Sección Dermatovenerológica del Departamento Nacional de Higiene, el galeno destacó que la abolición de la prostitución reglamentada, de 1936, era subproducto de la denuncia de la SN y del informe que había financiado la institución (Hackett, 1944).

Puente estaba satisfecho, ya que se había opuesto a la reglamentación durante años y estaba convencido que la nueva política promovía la continencia sexual entre los jóvenes. Es posible que éste exacerbara el lugar de los organismos internacionales frente a Hackett, al que consideró el representante de una institución que se proponía mesurar las políticas locales y de las que quizás pretendía obtener una fuente de financiamiento.

Pero más allá de esta situación, la conformación, en 1921, de la Comisión para la Represión de la Trata de Mujeres y Niños, junto con la instauración del convenio internacional, sería la institucionalización de circuitos de contacto entre funcionarios y organismos civiles. El convenio buscaba revalidar los compromisos previos en la hasta entonces llamada lucha contra la trata de blancas.

Esta "lucha" estaba compuesta por redes extensas que reunían a sociedades de socorro, al movimiento abolicionista, a organismos sanitaristas, a profesionales o fundaciones privadas, a actores que, con menor o mayor alcance, trazaron líneas de contactos internacionales yuxtapuestas, simultáneas, convergentes o divergentes. En torno a estas políticas, mediados por instituciones estatales o de la sociedad civil, se construyeron correas de circulación que articularon estrategias conjuntas y que aunaron escalas locales, regionales, y globales. Médicos, legisladores, políticos, sindicalistas y activistas desplegaron mítines de difusión y reuniones multilaterales con los que asentaron los reclamos abolicionistas.

La doctora Paulina Luisi fue un ejemplo canónico de la actividad de estas redes. Luisi nació en Entre Ríos, Argentina, hija de inmigrantes italianos y polacos, 
desarrollaría una actividad destacada en la vida política y social uruguaya. Fue la primera mujer en cursar la carrera de medicina en Uruguay, fundadora del Partido Socialista uruguayo y destacada promotora de valores feministas liberales, creó la primera organización sufragista oriental y fue una ferviente promotora del abolicionismo. Sus críticas al reglamentarismo se basaron en considerar que la inscripción de las prostitutas en el Estado como una necesidad social impostergable para proteger la salud masculina era falsa, por lo que cuestionó a los médicos y consumidores por ser la contraparte del proxenetismo. En su lugar, propuso una concepción integral de la salud que no se ocupara solo del varón, sino que también bregara por el bienestar femenino (LUISI, 1919).

Como impulsora del abolicionismo y el feminismo, Luisi fue parte de extensas redes a lo largo del globo, entre las que se destacó su participación en la Comisión de la SN dedicada a la lucha contra el tráfico de mujeres y niños, a pesar de que el Estado Uruguayo retardó su nombramiento oficial varios años. La comisión creada en el seno de la SN tuvo que lidiar con las dificultades para obtener legitimidad entre los Estados miembros. Los diversos convenios promulgados, como el firmado en septiembre de 1921, fue en un principio firmado solo por 13 de los 33 Estados que conformaron la SN.

La influencia de la galena uruguaya era doble: institucional, porque ocupó un lugar destacado en la SN, y también civil, ya que enlazó redes trasnacionales con las que recibía, traducía, y ponía en circulación saberes y alianzas entre abolicionistas, médicos, y legisladores, a través del dictado de cursos, de la traducción de libros, y de sus publicaciones de alcance internacional (LUISI, 1926). Por ejemplo, en sus contactos mediados por la red de la Federación Abolicionista Internacional y la Liga Internacional contra la Trata de Blancas se encontraba un grupo heterogéneo de varones y mujeres de variadas clases y posiciones sociales, participaban en ellos destacados miembros de la aristocracia europea, como: Lord Aberdeen (virrey de Irlanda), Avril Saint Croux (miembro de familia patricia francesa), Mme. Witt Schumberger (Consejo Nacional de Mujeres Francesas), la Infanta Isabel de Borbón (España), la Condesa Aguillar de Inestrilla (España), la Infanta Doña Paz (España), Mme. Leroy Allais (francesa), y la doctora Inés Mac 
Laren, una de las principales allegadas a Josephine Butler, fundadora del abolicionismo, entre otras (LUISI, 1919).

También organizó vínculos ligados a su profesión médica y política, entre los que reunió abolicionistas y socialistas, entre ellos los argentinos Ángel Gimenez, Alfredo Palacios, Telémaco Sussini, Baldomero Sommer, y Nicolás Repetto, miembros del Colegio Real de Medicina Británico, académicos de la Facultad de Medicina de París, y los doctores Skinner y Bronson Reynolds, de la burocracia sanitaria estadounidense.

En simultáneo a las actividades de Luisi, otros grupos activaron redes locales para derogar la reglamentación de la prostitución. La Asociación Argentina contra la Trata de Blancas participó, desde 1907, en los congresos internacionales convocados por los abolicionistas (Boletín del Patronato Real para la Represión de la Trata de Blancas, 1907). Simpatizantes de los proyectos abolicionistas promovieron la circulación de los discursos de Alfredo Palacios contra los proxenetas y lo señalaron como un modelo a seguir en la prensa abolicionista internacional (Boletín del Patronato Real para la Represión de la Trata de Blancas, 1907).

Durante el siglo XX, la agenda de la "trata de blancas" en la Argentina aunó esfuerzos con un amplio abanico de organizaciones políticas y sociales, en vistas de presionar al Estado para sancionar mayores herramientas represivas contra el proxenetismo. Para ello, convocó a miembros de la comunidad judía y, en su apoyo, el club israelita solicitó al Estado que colaborara en "la depuración de la colectividad de los elementos antisociales e inmorales" (Congreso de la Nación, 15/06/1910). En los debates en torno a la ley Palacios, en 1913, reunieron cartas de apoyo de la Federación Universitaria de Buenos Aires (624/13), de la Asociación Estudiantil Sarmiento (666/13), de plataformas intelectuales, como la Liga Nacional del Libre Pensamiento (656/3), y 62 folios con firmas de ciudadanos de la Ciudad de Buenos Aires (444/13). En 1917, presentaron credenciales similares al parlamento cuando Ángel Giménez, un diputado socialista, intentó acrecentar las herramientas punitivas del Estado contra el proxenetismo y, para ello, convocaron, también, a la Liga Feminista Nacional (180/17). 
Grupos civiles con primacía médica colaboraron con la promoción de la abolición de la prostitución reglamentada como demanda por una política integral contra enfermedades venéreas (BIERNAT, 2013). La Liga Argentina de Profilaxis Social, fundada por el galeno Alfredo Fernández Verano, movilizó desde 1921 amplios apoyos de la sociedad. Este grupo de galenos se dedicó a dictar conferencias e intentó incidir en la opinión pública argentina. Por su parte, semanarios masivos, como Caras y Caretas, dieron cuenta de sus actividades publicando fotografías de las campañas de recaudación (05/03/1921; p. 51), de conferencias en universidades nacionales (03/11/1923, p. 152), de conciertos de piano benéficos (03/11/1924, p. 18), y de los mítines en populares teatros de la ciudad capital (06/09/1924, p. 165 y 13/06/1925, p. 17), entre otras actividades. En suma, conjugaron una amplia campaña para ampliar las bases sociales y popularizar las nociones abolicionistas.

En un escenario de profusos canales de circulación, la Comisión contra el Tráfico de Mujeres y Niños de la SN escenificó un terreno de tensiones en la consolidación del proyecto pro-abolición de la prostitución reglamentada. Una vez promulgado el Convenio Internacional contra el Tráfico de Mujeres y Niños, en 1922 se compuso la comisión contra el tráfico de mujeres y niños con representantes de Gran Bretaña, Dinamarca, España, Francia, Italia, EE. UU., Japón, Uruguay, Polonia, y Rumania (BSN, 01/04/1922).

La comisión propuso medidas administrativas para registrar las tareas de los Estados en la materia. Entre ellas, se programó el envío de encuestas anuales para monitorear las políticas de los Estados nacionales. Argentina, que mantuvo una postura reticente a este tipo de incumbencias, dilataría sus respuestas hasta 1935. Efectivamente, la recepción de las acciones de la comisión era heterogénea, como también lo eran las posturas frente a los regímenes de administración de la compra y venta de servicios sexuales. Si, a finales del siglo XIX, varios países adhirieron al reglamentarismo, bajo la premisa de construir una forma de regulación moderna de la sexualidad, las presiones internacionales por abolir la prostitución derivaron en la abolición de las políticas regulatorias: en 1927 lo hizo Uruguay, luego Chile, en 1931, y continuó argentina con ordenanzas y leyes entre 1932 y 1936 (COMANDINI, 2017). 
En 1923, la representante norteamericana, Grace Abbot, impulsó un giro de inflexión en las dinámicas de discusión. Allí se posicionó por una política integral que bregara tanto por la reducción del tráfico como por la protección de la infancia. En cuanto al primer tópico, propuso la concreción de un comité técnico de especialistas que estudiara tanto las políticas que cada Estado tenía como, también, las redes de tráfico, la vida de los proxenetas, y sus tácticas para forzar a las mujeres a prostituirse (BSN, 1923, p. 200). Por otro lado, recomendó a la American Social Hygiene Association (ASHA), fundada en 1913, como una plataforma para interconectar a organizaciones dedicadas al combate de enfermedades venéreas y la prostitución, como coordinadora del trabajo de investigación, y nombró al abogado Bascom Johnson para que dirigiera el trabajo de campo, quien durante la Primera Guerra Mundial había comandado campañas de profilaxis entre los soldados norteamericanos. La propuesta no fue recibida de forma unánime. En la reunión en la que se aprobó la iniciativa, obtuvo 5 votos a favor (Italia, Polonia, España, EE. UU., y Uruguay), 3 en contra (Francia, Japón, y Rumania), y 1 abstención (Dinamarca).

Para la realización de esta investigación, que contaría con 2 etapas (192324 y 1924-27), la delegada estadounidense ofreció 75 mil dólares a la SN, donados por la Fundación Rockefeller. La comisión de "especialistas y técnicos" reunió a personas de pertenencia heterogénea, entre las que estaban Paulina Luisi. En 1924, basados en los primeros datos, la comisión acusaría a la política reglamentaria como el principal factor explicativo de tráfico y, posiblemente, en este movimiento consolidó un signo univoco de interpretación de la prostitución en torno a la coacción.

Aunque Luisi había impulsado al abolicionismo durante la década de 1920, no se sintió conforme frente a los primeros resultados del informe. Junto a otros colegas, señalaron los límites de la información volcada en sus páginas por investigadores de habla inglesa que, a su parecer, exaltaron la responsabilidad de los actores latinoamericanos (BSN, 01/07/1924). El documento influenciado por los angloparlantes culpabilizaba a países de habla hispana por mantener el reglamentarismo, cuestión con la que disentiría Paulina Luisi, por considerarla tendenciosa (KNEPPER, 2011). 
En 1924, la comisión seguía dividida, no todos acordaban con establecer el fin de la política reglamentaria como una sugerencia directa de la comisión. Dinamarca, Gran Bretaña, Polonia, y Uruguay apoyaron la propuesta de rechazar explícitamente la política reglamentaria. La comisión propuso que se ampliaran las atribuciones de las sociedades de beneficencia y de socorro. Como punto final, siguiendo la sugerencia del principal impulsor del estudio, se sancionó la creación de un nuevo organismo: la comisión consultiva de la protección de mujeres y niños. Esto resultaría el sello del paso de una perspectiva plenamente criminalística del tráfico de personas a un enfoque de políticas sociales. Dentro del cual se creó un consejo asesor, ocupado de políticas de la niñez y otro del tráfico de personas (BSN, 01/06/1924).

La protección de las mujeres y niños tenía una doble dimensión de discusión. En primer lugar, criminológica, ya que se buscaron formas de restringir sus viajes solo, por considerarlos frágiles y desprotegidos. Esto, creían, limitaría las capacidades de los proxenetas para movilizar mujeres a la periferia. En segundo lugar, también destacaba su vuSNerabilidad social. Las intenciones por desintegrar las redes, se creían, debían acompañarse con la protección a las trabajadoras y sus infantes, como así también la reinserción de las prostitutas en su condición maternal, como estrategia principal para encausar su vida.

En 1925, este paso administrativo asumió un nuevo empuje. Se constituyó la Comisión para la Represión de la Trata de Blancas y la Protección de la Infancia, agrupada bajo la denominación de cuestiones sociales y de la infancia (BSN, 01/05/1925). La misma se formó por miembros designados directamente por los gobiernos. Paulina Luisi, que anteriormente era invitada por su lugar en el movimiento abolicionista, reafirmó su lugar de pertenencia apoyada por Uruguay. Se determinó un grupo de asesores que institucionalizaron el lugar de las asociaciones de socorro y beneficencia: la Oficina Internacional para la Supresión del Tráfico de Personas, la Organización Internacional Femenina, la Organización Judía para la Protección de las Mujeres, la Federación de las Uniones Nacionales de Amigas de las Jóvenes, y la Asociación Católica Internacional de Instituciones Protectoras de Jóvenes. 
La exposición del resultado final del informe, en 1927, reflotó nuevamente el asunto en el centro de la SN. Este organismo discutió la edad de matrimonio de las mujeres, sugirió que los Estados controlasen las formas de contratación de mujeres en musichalls o ambientes artísticos, invitó a la expulsión y deportación de proxenetas como principal política punitiva, que, como señalamos en los apartados anteriores, fue adoptada por Argentina como una abierta posición abolicionista, indicando el fracaso de las políticas reglamentarias. También se reafirmó la necesidad de estimular la "recuperación” de las mujeres que eran sometidas a la prostitución y su retorno como "madres de familia”, para lo cual se apeló a las sociedades de beneficencia. La comisión también recomendó a las policías incluir mujeres en las fuerzas para tener mayor alcance entre las prostitutas. Aunque la policía de la Capital Federal envió una carta secundando la moción, las mujeres ingresarían a la fuerza en 1947 (GALEANO; KAMINSKY, 2011). También se promovieron legislaciones que tendieran a restringir la circulación de material erótico y pornográfico, que se creía favorecer la corrupción femenina (BSN, 04/09/1927). Nuevamente, Paulina Luisi renegó algunos aspectos del resultado final del informe, entre ellos los que relegaban a los países hispanos (BSN, 01/08/1927).

Los usos del resultado del informe preparado por la comisión técnica de la SN no solo causaron el interés de la prensa, sino también de varios Estados nacionales que cuestionaron los usos de una investigación financiada por EE. UU. Aquellos aún aferrados a mantener una política que reglamentaba los burdeles destacaron que la intención de sus promotores era buscar culpabilizar a sus Estados nacionales del crimen de proxenetismo.

Argentina, Francia, y Polonia desafiaron los usos políticos del informe y consideraron que dañaba el honor de sus naciones. Los delegados desplegaron distintas estrategias en vistas de preservar el prestigio nacional, que sentían amenazado. El polaco destacó el lugar de las instituciones benéficas y de socorro de su país en el rescate de mujeres. El delegado español, en contraste, apoyó los resultados y acusó a los otros delegados que debían estar contentos porque solo la verdad podría colaborar en "acabar con los rufianes". Para él la muestra de que “las mujeres españolas son explotadas por traficantes españoles” puede ayudar 
a extender la "reprobación de la humanidad" sobre estas prácticas, en vez de asociarla a problemas extranjeros (BSN, 16/11/1927).

En la perspectiva de presionar por un cambio en las políticas en torno a la compra y venta de sexo, hubo un progresivo énfasis sobre la construcción de un imaginario de Latinoamérica que tendía a resaltar la idea de desorden o falta de control. Así, al igual que para el delegado francés, una de las principales tareas era la de forzar a los Estados del sur a adherir a los convenios internacionales, para el representante polaco, el territorio sudamericano era el centro del problema. Desde su óptica, todos los proxenetas del mundo habían trabajado en algún momento en estos países, porque allí, nunca serían castigados (BSN, 12/02/1928).

El delegado polaco afirmó que no podía compararse la situación de las mujeres extranjeras en los burdeles de Latinoamérica con las que había en países como el propio y el francés. Para este representante, esto explicaría la falta de cooperación con material informativo por parte de Estados como Argentina, Brasil, o Uruguay con las tareas emprendidas. Llamaba a no confiar en la política de expulsión de estos países que, por ejemplo, habían recibido muchas mujeres de Hungría y Rusia que, una vez deportadas, no retornaban a sus países. A su vez, reforzaba la inviabilidad de esta política dimensionando que solo para una ciudad como Buenos Aires no alcanzaría financiamiento alguno para repatriar ciudadanos (Memorandum to the Council on the Comments Submitted by the Government Regarding Part II of the Report of Special Body of Experts, 22/11/1927).

Las autoridades argentinas rechazaron el lugar que la comisión les otorgaba en el escenario del comercio internacional. En una carta (1927), en respuesta al primer apartado del informe, el delegado argentino señalo que, en su país, este fenómeno estaba prácticamente en proceso de desaparición. Razón que adjudicaba a la sanción de la Ley No. 9.143, la Ley Palacios, que restringía el tráfico de mujeres y niños con fines de explotación sexual y resultaría en un modelo legislativo internacional (InfoLeg. Ley 9143, Congreso de la Nación Argentina). 
El funcionario asociaba esta tendencia decreciente con las dificultades que la guerra había traído para realizar viajes de este tipo. Para el funcionario, la tendencia a asociar al país a estas prácticas con Argentina era parte de una campaña internacional para dañar la integridad del país. También afirmó que, en gran parte, los problemas del Estado se debían a las debilidades morales de la clase media europea que había llegado al país tras los estragos de la guerra. Desmintió que las mujeres llegaran vírgenes, es decir, que ya vendrían "corrompidas" de Europa. Dijo también que Buenos Aires era una ciudad más sana "moral y físicamente que otras más antiguas y con mejores legislaciones". Por último, señaló que los ingresos no podían ser limitados, porque los varones y mujeres ingresaban con papeles. Por esta razón, solo podría habilitarse la intervención del Estado si la victima denunciaba a sus explotadores, cosa que raramente sucedía, ya que, para el funcionario, las prostitutas buscaban independizarse en un régimen clandestino (Memorandum to the Council on the Comments Submitted by the Goverment Regarding Part II of the Report of Special Body of Experts, 30/11/1927).

En 1929, la comisión retomó sus sugerencias en torno al castigo de proxenetas. Su principal objetivo era lograr la adhesión de los Estados a los convenios previos, para que asumieran compromisos contra el tráfico. Los informes y las denuncias presentadas ante la comisión por el International Bureau for the Suppression of Traffic of Women and Children ubicaron entre los mayores responsables del tráfico a India, Egipto, y Argentina (BSN, 01/06/1929).

En 1930, la comisión festejó el pronunciamiento de Uruguay contra el tráfico de persona y el ordenamiento de sus informes periódicos (BSN, 01/02/1930). Se auspició la organización de un congreso en Varsovia, reconociendo el lugar simbólico que ocupaba Polonia, país del que se creía eran secuestradas un gran número de mujeres.

Las tensiones entre las alas reglamentarias y abolicionistas siguieron marcando la agenda de los organismos. Algunos asesores promovieron que se prohibiera el ingreso de prostitutas inscriptas en burdeles a los países, lo que desató el rechazo entre los miembros abolicionistas por considerar que reforzaba el sistema reglamentario. Un año más tarde, la política de sugerencias 
fue cambiada por un comunicado donde el comité denunció a los países, desde las páginas del boletín de la SN, que no había suscripto al convenio de 1921. Los países latinoamericanos destacados fueron Argentina, Bolivia, República Dominicana, Guatemala, Haití, Honduras, Nicaragua, Venezuela, El Salvador, México, y Paraguay, que se sumaron a otra lista de países en los que estaban Etiopía, Liberia, y el Estado libre de Irlanda (BSN, 01/04/1932).

Durante la década de 1930, la comisión procuró ampliar su agenda, recolocó como un factor central de debate político las atenciones de las enfermedades venéreas, sugiriendo el tratamiento universal de las enfermedades venéreas (BSN, 01/07/1936). De este modo, se cerraba un corolario de sentidos: mujer honesta asociada a la maternidad, protección del niño para la reproducción de la "raza", y tratamiento del varón ante las enfermedades que por su incontrolable deseo podrían propiciar la "contaminación de la familia". En este sentido, se destacaron los avances de las leyes de profilaxis sociales sancionadas en Argentina y Uruguay (BSN, 01/03/1937).

La SN tendió a asumir que la abolición de la reglamentación debía ser aceptada por todos los Estados. En contraste con Argentina, otros países o jurisdicciones de América Latina fueron más permeables en las transformaciones de sus legislaciones y dieron fin rápidamente a las legislaciones reglamentarias. Así lo hizo Cuba (1925), República Dominicana (1926), Montevideo (1927), Nicaragua (1928), y Chile (1931). Los primeros registros de fin del sistema reglamentado se encuentran en Avellaneda (1916) y Santa Fe (1933). Finalmente, un bloque de países lanzaría, con mayor fuerza desde 1934, una ofensiva que asoció la legislación reglamentaria al tráfico de personas. Entre sus impulsores estuvieron Bélgica, Cuba, Checoslovaquia, Gran Bretaña, los Países Bajos, Polonia, Suiza, y los EE. UU.

\section{Conclusión}

El rufián - el proxenetismo como práctica global - articuló figuras que ocuparon progresivamente la escena argentina anudado con la sístole y la diástole de las crisis políticas, sociales, y culturales del proyecto liberal que alcanzaron su auge en la década de 1930. La apropiación de dinero por parte de 
varones de mujeres que vendieron servicios sexuales fue entonces interpretada y puesta en circulación en circuitos locales y globales, articulando los temores frente a los efectos del capitalismo liberal. Como sostuvimos aquí, los procesos de re-imaginación nacional que redefinieron los vínculos entre sexualidad y raza y los límites sexuados, étnicos, y clasistas de su ciudadanía.

Las redes yuxtapuestas de funcionarios públicos y miembros de organizaciones civiles construyeron una agenda global en torno a la trata de blancas. Estos contactos proporcionaron un espacio en el que se dirimieron recomendaciones políticas en torno a las políticas estatales sobre la venta y compra de sexo. En contraste con otras acciones emprendidas por la SN, la comisión tuvo mayor impacto en las políticas locales y colaboró en la propagación de la abolición de la prostitución reglamentada. Por último, la elaboración del informe y las políticas de monitoreo revelan las tensiones en la definición de políticas globales de población, en general, y en torno a la prostitución, en particular.

El sexo de las naciones, su sexualidad, coaguló así las transformaciones turbulentas de las nociones de los actores del siglo XX, que fueron virando su esperanza en la posibilidad de crecimiento cualitativo y cuantitativo de obreros, soldados, y consumidores que ocuparan la Argentina. De la esperanza puesta en los migrantes blancos a los proxenetas, el abrazo a un pasado criollo hasta la emergencia de un ideal de raza en construcción que debía mejorarse para lograr el desarrollo, todos ellos se entrelazaron en sentidos polisémicos sobre la norma sexual de la Argentina moderna. 


\section{Referências}

ADAMOVSKY, Ezequiel. La cuarta función del criollismo y las luchas por la definición del origen y el color del ethnos argentino (desde las primeras novelas gauchescas hasta c. 1940). Boletín del Instituto de Historia Argentina y Americana Dr. Emilio Ravignani, Buenos Aires, n. 41, p. 50-92, 2014.

ADAMOVSKY, Ezequiel. A strange emblem for a (not so) white nation: la morocha Argentina in the Latin American racial context, c. 1900-2015. Journal of Social History, Oxford, v. 50, n. 2, p. 386-410, 2016.

ALBERTO, Paulina; ELENA, Eduardo. Rethinking race in modern Argentina. [S. l.]: Cambridge University Press, 2016.

APPELBAUM, Nancy P.; MACPHERSON, Anne S.; ROSEMBLATT, Karin Alejandra. Race and nation in modern Latin America. [S. l.]: University of North Carolina Press, 2003.

ARIAS, Julio; RESTREPO, Eduardo. Historizando raza: propuestas conceptuales y metodológicas. Crítica y Emancipación, Buenos Aires, v. 2, n. 3, p. 45-64, 2010.

AYARRAGARAY, Lucas. Cuestiones y problemas argentinos contemporáneos... [S. l.]: L. J. Rosso, 1937. v. 1.

BARRANCOS, Dora. Feminismo, trata y nuevos tratos. Mora, Buenos Aires, v. 14, n. 2, p. 161-164, 2008.

BARRÉS, Mariano. El hampa y sus secretos. Buenos Aires: López, 1934.

BARTLEY, Paula. Prostitution: prevention and reform in England, 1860-1914. [S. l.]: Routledge, 2012.

BEMBO, Martín. La mala vida en Barcelona. Barcelona: Manucci, 1912.

BEN, Pablo. Historia global y prostitución porteña: el fenómeno de la prostitución moderna en Buenos Aires, 1880-1930. Revista de Estudios Maritimos y Sociales, Buenos Aires, n. 5-6, p. 13-26, 2014.

BIERNAT, Carolina. Médicos, especialistas, políticos y funcionarios en la organización centralizada de la profilaxis de las enfermedades venéreas en la Argentina (1930-1954). Anuario de Estudios Americanos, Sevilla, v. 64, n. 1, p. 257-288, 2007.

BIERNAT, Carolina. Entre el abolicionismo y la reglamentación: prostitución y salud pública en Argentina (1930-1955). Cuadernos del Sur, Buenos Aires, v. 40, n. 3, p. 29-48, 2013. 
BIERNAT, Carolina; RAMACCIOTTI, Karina. La tutela estatal de la madre y el niño en la Argentina: estructuras administrativas, legislación y cuadros técnicos (1936-1955). História, Ciências, Saúde - Manguinhos, Rio de Janeiro, v. 15, n. 2, p. 331-351, 2008.

CAIMARI, Lila M. Mientras la ciudad duerme: pistoleros, policías y periodistas en Buenos Aires, 1920-1945. [S. l.]: Siglo Veintiuno, 2012.

CHAUMONT, Jean-Michel; RODRIGUEZ GARCIA, Magaly; SERVAIS, Paul.

Trafficking in women 1924-1926. The Paul Kinsie Reports for the League of Nations. Geneva: United Nations Publications, 2017. v. 1.

COMANDINI A. C. G. La prostitución reglamentada en Latino América en la época de la modernización. Los casos de Argentina, Uruguay y Chile entre 1874 y 1936. Historia 396, Valparaíso, v. 7, n. 1, p. 89-118, 2017.

CORBIN, Alain. Women for hire: prostitution and sexuality in France after 1850. [S. l.]: Harvard University Press, 1996.

DEUTSCH, Sandra McGee. Contra "el gran desorden sexual": los nacionalistas y la sexualidad, 1919-1940. Sociohistórica, Buenos Aires, n. 17-18, p. 127-150, 2005.

DEVOTO, Fernando J. El revés de la trama: políticas migratorias y prácticas administrativas en la Argentina (1919-1949). Desarrollo Económico, [s. l.], p. 281304, 2001.

GALEANO, Diego. Las conferencias sudamericanas de policías y la problemática de los delincuentes viajeros, 1905-1920. In: BOSHOSLAVSKY, Ernesto; SCHETTINI, Cristiana; CAIMARI, Lila (org.). La policía en perspectiva histórica. Argentina y Brasil (del siglo XIX a la actualidad). Buenos Aires: [s. n.], 2009. 1 CD-ROM.

GALEANO, Diego; KAMINSKY, Gregorio. Mirada (de) uniforme: historia y crítica de la razón policial. Buenos Aires: Teseo, 2011.

GÁLVEZ, Manuel. La trata de blancas. [S. l.]: Tragant, 1905.

GARCÍA, Magaly Rodríguez. The League of Nations and the moral recruitment of women. International Review of Social History, Amsterdam, v. 57, n. S20, p. 97128, 2012.

GARGUIN, Enrique. "Los argentinos descendemos de los barcos": the racial articulation of middle class identity in Argentina (1920-1960). Latin American and Caribbean Ethnic Studies, [s. l.], v. 2, n. 2, p. 161-184, 2007. 
GILFOYLE, Timothy J. Prostitutes in history: from parables of pornography to metaphors of modernity. The American Historical Review, Washington, v. 104, n. 1, p. 117-141, 1999.

GIMÉNEZ, Angel M. Contra la reglamentación de la prostitución: abolición de las ordenanzas municipales y profilaxis de las enfermedades venéreas - proyectos y discursos pronunciados por el Consejo Deliberante de Buenos Aires, en las sesiones... [S. l.]: A. Cantiello, 1919.

GIMÉNEZ, Angel M. La reglamentación de la prostitución y la represión de la trata de blancas ante la justicia penal. [S. l.]: La Vanguardia, 1930.

GUY, Donna. Sex and danger in Buenos Aires. Prostitution, Family, and Nation in Argentina. Lincoln: University of Nebraska Press, 1991.

HACKETT, Lewis. Diary, Rockefeller Archive, 1944

HERZOG, Dagmar. Sexuality in Europe: a twentieth-century history. [S. l.]:

Cambridge University Press, 2011. v. 45.

JORDAN, Jane. Josephine Butler. [S. l.]: Hambledon Continuum, 2007.

KALIFA, Dominique. Les bas-fonds. Histoire d'un imaginaire. [S. l.]: Le Seuil, 2013.

KNEPPER, Paul. International crime in the $20^{\text {th }}$ century: the League of Nations Era, 1919-1939. [S. l.]: Springer, 2011.

LAITE, Julia. Common prostitutes and ordinary citizens: commercial sex in London, 1885-1960. [S. l.]: Springer, 2011.

LAITE, Julia. Between Scylla and Charybdis: women's labour migration and sex trafficking in the early twentieth century. International Review of Social History, Amsterdam, v. 62, n. 1, p. 37-65, 2017.

LINARES, Luciana. La ley en los cuerpos ajenos. Prostitución rural y tensiones entre práctica y discurso médico en relación con las enfermedades venéreas. El caso del sudeste bonaerense en las primeras décadas del siglo XX. [S. l.]: [s. n.], 2016.

LUGONES, Leopoldo. La patria fuerte. [S. L.]: L. Bernard, 1930.

LUISI, Paulina. Una vergüenza social: la reglamentación de la prostitución conferencia leída en la Asociación Cristiana de Jóvenes de Buenos Aires el 13 de octubre de 1918. Buenos Aires: Juan Perrotti, 1919. 
LUISI, Paulina. El problema de la prostitución: ¿abolicionismo o reglamentarismo? Montevideo: La Industrial, 1926.

MILANESIO, Natalia. Redefining men's sexuality, resignifying male bodies: the Argentine law of anti-venereal prophylaxis, 1936. Gender \& History, [s. l.], v. 17, n. 2, p. 463-491, 2005.

MIRANDA, Marisa A. Buenos Aires, entre Eros y Tánatos: la prostitución como amenaza disgénica (1930-1955). Dynamis, Granada, v. 32, n. 1, p. 93-113, 2012.

MÚGICA, María Luisa. Sexo bajo control: la prostitución reglamentada - un escabroso asunto de política municipal - Rosario entre 1900 y 1912. [S. l.]: Universidad Nacional de Rosario, 2001.

NOUWEN, Mollie Lewis. Oy, my Buenos Aires: Jewish immigrants and the creation of Argentine national identity. [S. l.]: UNM Press, 2013.

PAREJA, Ernesto M. La prostitución en Buenos Aires. [S. l.]: Tor, 1937.

PINAZO, Matías. Delitos y delincuentes (el trasplante siniestro). Buenos Aires: Cúneo, 1918.

PISCITELLI, Adriana. Revisiting notions of sex trafficking and victims. Vibrant: Virtual Brazilian Anthropology, Brasília, v. 9, n. 1, p. 274-310, 2012.

QUEIROLO, Graciela. Género y sexualidad en tiempos de males venéreos (Buenos Aires, 1920-1940). Nomadías, Santiago de Chile, n. 17, p. 67-87, 2014.

QUEVEDO, JOSÉ. El sindicalismo y el problema de la prostitución, Buenos Aires, 1952. Buenos Aires: Laboratorio Social Argentino de la Peña Sindicalista, 1952.

REVENIN, Régis. Homosexualité et prostitution masculines à Paris, 1870-1918. [S. l.]: L'Harmattan, 2005.

ROEDIGER, David R. The wages of whiteness: race and the making of the American working class. [S. l.]: Verso, 1999.

SCARZANELLA, Eugenia. La infancia latinoamericana y la Sociedad de las Naciones: derechos, salud y bienestar. In: POTTHAST, Barbara; CARRERAS, Sandra (ed.). Entre la familia, la sociedad y el Estado. Niños y jóvenes en América Latina (siglos XIX-XX). Frankfurt/Madrid: Vervuert/Iberoamericana, 2005. p. 203-232. 
SCHETTINI, Cristiana. Conexiones transnacionales: agentes encubiertos y tráfico de mujeres en los años 1920. Nouveaux Mondes, Mondes Nouveaux, Paris, v. 1, p. 1-25, 2014.

SIMONETTO, Patricio. Intimidades disidentes. Intersecciones en las experiencias de homosexuales y lesbianas en Buenos Aires durante los sesenta y setenta. Trashumante: Revista Americana de Historia Social, Medellín, n. 11, p. 28-50, 2018a.

SIMONETTO, Patricio. Pagar para ser hombre. Prácticas y sentidos de la compra de sexo en los testimonios judiciales de trabajadores. Provincia de Buenos Aires, 1936-1960. Revista Historia y Justicia, Santiago de Chile, n. 10, p. 14-41, 2018b.

SIMONETTO, Patricio. El dinero no es todo. La compra y venta de sexo en la Argentina del siglo XX. Buenos Aires: Biblos, 2019a.

SIMONETTO, Patricio. Los rufianes de Buenos Aires: prácticas de proxenetismo global en la Argentina, 1924-1936. Varia Historia, Belo Horizonte, v. 35, n. 67, p. 311-344, 2019b.

STEARNS, Peter N. Sexuality in world history. [S. l.]: Routledge, 2017.

TENTI, María Mercedes. Los estudios culturales, la historiografía y los sectores subalternos. Trabajo y Sociedad, Santiago del Estero, v. 16, n. 18, p. 317-329, 2012.

THÉBAUD, Françoise. La Primera Guerra Mundial: ¿la era de la mujer o el triunfo de la diferencia sexual? [S. l.]: Taurus, 1993.

URBANYI, Pablo. El mercado erótico. Buenos Aires: Análitica, 1976.

VALOBRA, Adriana María. Feminismo, sufragismo y mujeres en los partidos políticos en la Argentina de la primera mitad del siglo XX. @mnis: Revue de Civilisation Contemporaine Europes/Amériques, Brest, n. 8, p. 1-11, 2008.

WALKOWITZ, Judith R. Prostitution and Victorian society: women, class, and the State. [S. l.]: Cambridge University Press, 1982.

YARFITZ, Mir. Polacos, white slaves, and stille chuppahs: organized prostitution and the Jews of Buenos Aires, 1890-1939. Advisor: José C. Moya. 2012. 345 S. Thesis (Ph.D. in Philosophy in History) - University of California, Los Angeles, 2012. 


\section{Publicaciones periódicas}

AA.VV. (1927) Memorandum to the Council on the Comments Submitted by the Government Regarding Part II of the Report of Special Body of Experts.

AA.VV. (1927) Report of Special Body of experts of the League of Nations. V. I \& II. Toronto University Library.

Boletín de la Sociedad de Naciones (BSN), Hemeroteca Digital, Biblioteca Nacional de España.

Boletín del Patronato Real para la Represión de la Trata de Blancas, Hemeroteca Digital, Biblioteca Nacional de España.

Caras y Caretas.

Crítica.

El Gladiador.

Expedientes del Congreso de la Nación Argentina.

La Opinión.

La Razón. 